\title{
Induction of proto-oncogene fos transcription through the adenylate cyclase pathway: characterization of a cAMP-responsive element
}

\author{
Paolo Sassone-Corsi, Jane Visvader, Louis Ferland, Pamela L. Mellon, and Inder M. Verma \\ The Salk Institute, San Diego, California 92138 USA
}

\begin{abstract}
Transcription of proto-oncogene fos is induced by elevated levels of intracellular cAMP. We report that human c-fos promoter recombinants transfected into rat pheochromocytoma cells (PC12) and human choriocarcinoma cells (JEG-3) are induced by stimulation of adenylate cyclase and that this induction is diminished considerably in the mutant PC12 cell line A126-1B2, which is deficient in cAMP-dependent protein kinase II. An element centered at position -60 of the $c$-fos promoter, which encompasses a consensus cAMP response element (CRE), is sufficient to confer cAMP responsiveness to a herpes thymidine kinase/CAT fusion gene. The specific binding of a nuclear protein to the c-fos CRE can be competed by the somatostatin and $\alpha$-chorionic gonadotropin $(\alpha-C G)$ promoter regions that contain CREs. Gel mobility shift assays with double-stranded oligonucleotides containing either the wild-type or mutated c-fos CRE sequence have demonstrated that binding occurs only to the wild-type CRE. The nuclear factor binding to the c-fos CRE is likely to be transcription factor CREB (CRE nuclear binding protein), because an affinity-purified 43-kD CREB isolated from PC12 cells binds efficiently in a DNA footprinting assay. Thus, regulation of the c-fos gene transcription appears to involve a mechanism common to many genes that respond to cAMP as a second message leading to cell growth and differentiation.
\end{abstract}

[Key Words: Protein kinase A; PC12 cells; nuclear factor CREB]

Received August 10, 1988; revised version accepted October 11, 1988.

The genomic response of a cell to mitogens and differentiation agents is manifested by the transcriptional induction of several cellular genes. Prominent among those are nuclear oncogenes fos, myc, and jun, which belong to the class referred to as 'immediate early genes' or 'competence genes' (Cochran et al. 1983; Greenberg and Ziff 1984; Verma and Sassone-Corsi 1987). Although the precise function of these early response genes in growth control and differentiation is not understood, it is likely that some of them are involved in the $G_{0}$ to $G_{1}$ transition in the cell cycle.

We have been interested in studying the role of the proto-oncogene fos in growth, differentiation, and development. c-fos is the cellular cognate of the transforming gene fos of FBJ murine osteosarcoma virus (FBJ-MSV), which induces bone tumors in vivo and transforms fibroblasts in vitro (Verma 1986). Expression of the c-fos gene is induced rapidly and transiently in a variety of mammalian cell types by a large array of stimuli (Greenberg and Ziff 1984; Kruijer et al. 1984; Muller 1986; Morgan et al. 1987). Induction of the c-fos gene occurs at the transcriptional level, is independent of new protein synthesis, and is enhanced in the presence of protein synthesis inhibitors (Greenberg and Ziff 1984; Mitchell et al. 1986; Greenberg et al. 1987). Evidence to date indicates that at least two cellular pathways are involved in c-fos induction: one that requires protein kinase $\mathrm{C}$ activation and the other involving adenylate cyclase. In the former case, growth factors increase intracellular degradation of phosphoinositols, resulting in the production of diacylglycerol (DAG) and mobilization of $\mathrm{Ca}^{2+}$, which activates protein kinase $C$. Such a cascade of events results in the modification and consequent activation of transcriptional factors such as AP-1, NF- $\mathrm{BB}$, and others (Sen and Baltimore 1986; Angel et al. 1987; Lee et al. 1987; Sorger et al. 1987). The activation of c-fos gene transcription by phorbol esters involves a trans-acting factor that is distinct from AP-1, termed SRF (serum responsive factor). It has been characterized by a number of laboratories (Gilman et al. 1986; Prywes and Roeder 1986; Treisman 1986) and appears to be responsible for transcriptional activation of the fos promoter by TPA, serum (Gilman et al. 1986; Treisman 1986; Greenberg et al. 1987), epidermal growth factor (EGF) (Prywes and Roeder 1986, fibroblast growth factor (FGF), and nerve growth factor (NGF) (Sheng et al. 1988; Visvader et al. 1988) upon binding to the dyad symmetry element (DSE), which is located $\sim 300$ bp upstream from the c-fos 
cap site (Treisman 1985; Gilman et al. 1986).

The c-fos gene is also inducible by agents that elevate intracellular levels of cAMP such as dibutyryl-cAMP, forskolin, or cholera toxin (Curran and Morgan 1985; Greenberg et al. 1985; Kruijer et al. 1985; Bravo et al. 1987). cAMP mediates the hormonal induction of numerous eukaryotic genes in several cell types (Terao et al. 1983; Bravo et al. 1987; Delegeane et al. 1987; Silver et al. 1987). Recent results strongly implicate the catalytic subunit of the cAMP-dependent protein kinase II as the mediator of cAMP action on gene expression (Van Buskirk et al. 1985). Whether or not the $R_{\text {II }}$ subunit is involved, it appears certain that a protein factor exists, which links kinase activation with transcription of cAMP-responsive genes. Such a nuclear factor has already been identified (Montminy and Bilezikjian 1987). It binds to the sequence TGACGT of the rat somatostatin gene, which represents the CAMP-responsive element (CRE). It is termed CREB (CRE nuclear binding protein) and is similar, if not identical, to nuclear factor ATF, which binds homologous sequences in most early adenovirus promoters (Hurst and Jones 1987; Lin and Green 1988; Sassone-Corsi 1988). In adenovirus, ATF appears to mediate the trans-activation function of the E1A product (Lin and Green 1988; Sassone-Corsi 1988). Interestingly, it has also been shown that c-fos promoter is trans-activated by E1A (Sassone-Corsi and Borrelli 1987). The sequence TGACGT is present in most cAMP-responsive genes, which are induced rapidly by cAMP (Sassone-Corsi 1988). The same sequence is also present in the c-fos promoter, leading us to investigate whether it is involved in the c-fos gene response to cAMP. We find that this element, centered at position -60 , confers cAMP responsiveness to a heterologous promoter and binds a nuclear factor that has characteristics similar to CREB. We suggest that c-fos activation by cAMP requires the post-translational modification of the CREB-like protein. Such a modification is likely to be phosphorylation because c-fos promoter induction by cAMP is reduced greatly in the mutant PC12 cell line A126-1B2, which is deficient in cAMP-dependent protein kinase II.

\section{Results}

cAMP inducibility of the c-fos promoter in transiently transfected cells

In PC12 cells, expression of the c-fos gene is induced by dibutyryl-cAMP, forskolin, and cholera toxin. This induction is rapid and transient, similar to that observed with other inducing agents (Verma 1986). To characterize cAMP-responsive sequences within the c-fos promoter, we fused fragments derived from the c-fos $5^{\prime}$ flanking region to the bacterial reporter gene for chloramphenicol acetyltransferase (CAT) (Fig. 1A). Promoter activity was determined by transient assay after calcium phosphate transfection of the fos-CAT fusion constructs into PC12 cells. To assess nonspecific effects of cAMP on gene expression, a plasmid containing the
SV40 promoter fused to the CAT gene was used as a control (pSV2CAT) (Gorman et al. 1982). We tested whether the regulation of the transfected c-fos promoter by cAMP would be analogous to that observed for the endogenous gene by treating the transfected cells with forskolin. As shown in Figure 1B (lanes 3 and 4), a 15fold induction of the c-fos-CAT fusion gene /containing 404 bp upstream of the c-fos promoter) is observed after the addition of forskolin, whereas expression from the SV40 promoter is unchanged (lanes 1 and 2).

We also examined c-fos induction by cAMP in another endocrine cell line, JEG-3, a placental trophoblast cell line derived from a human choriocarcinoma. A 12-fold induction by forskolin is also observed when the c-fosCAT fusion gene is transfected into JEG-3 cells (Fig. 1D; lanes 1 and 2). Because induction of the c-fos gene in this cell line has not been reported previously, we studied the effect of cAMP on the endogenous gene by Northern blot analysis of RNAs purified 1 and $18 \mathrm{hr}$ after forskolin treatment. As shown in Figure 1D, there is a marked increase in c-fos mRNA $1 \mathrm{hr}$ after forskolin treatment, (lanes 3 and 4), whereas no induction is observed after 18 hr (lanes 5 and 6). These results demonstrate that stimulation of c-fos expression by forskolin in JEG-3 cells is similar to that described in PC12 cells and that in either cell type, the episomal conformation of the gene does not alter cAMP responsiveness.

\section{Induction of the $c$-fos gene involves cAMP-dependent protein kinase II}

Agents that elevate intracellular levels of cAMP induce the transcription of several cellular genes by activating cAMP-dependent protein kinase II. As reported for the rat somatostatin gene, the studies using the PC12 mutant cell line A126-1B2 indicate the possible requirement of a specific kinase for cAMP-induced expression (Montminy et al. 1986). A126-1B2 cells have normal levels of cAMP-dependent protein kinase I activity but are markedly deficient in type II activity (Van Buskirk et al. 1985). In contrast to the 15-fold stimulation observed in wild-type PC12 cells, there is little or no stimulation of c-fos promoter activity upon treatment with forskolin of the A126-1B2 cells transfected with the fos-CAT fusion plasmid (Fig. 1B, lanes 7 and 8). The pSV2CAT control shows the same profile as in PC12 wild-type cells (lanes 5 and 6). Similar results were obtained using the RNase protection assay, with a c-fos-CAT SP6-derived probe and RNA from the transiently transfected PC12 cells (Fig. 1C, lanes 1-4). Thus, c-fos induction by cAMP involves the activity of the cAMP-dependent protein kinase II. This observation suggests that phosphorylation of the nuclear factor required for c-fos induction by cAMP is possibly involved in transcriptional activation.

\section{DSE is not involved in CAMP induction}

The c-fos enhancer contains a sequence element, termed serum-responsive element (SRE), which is constituted by DSE. It mediates the transcriptional response to 


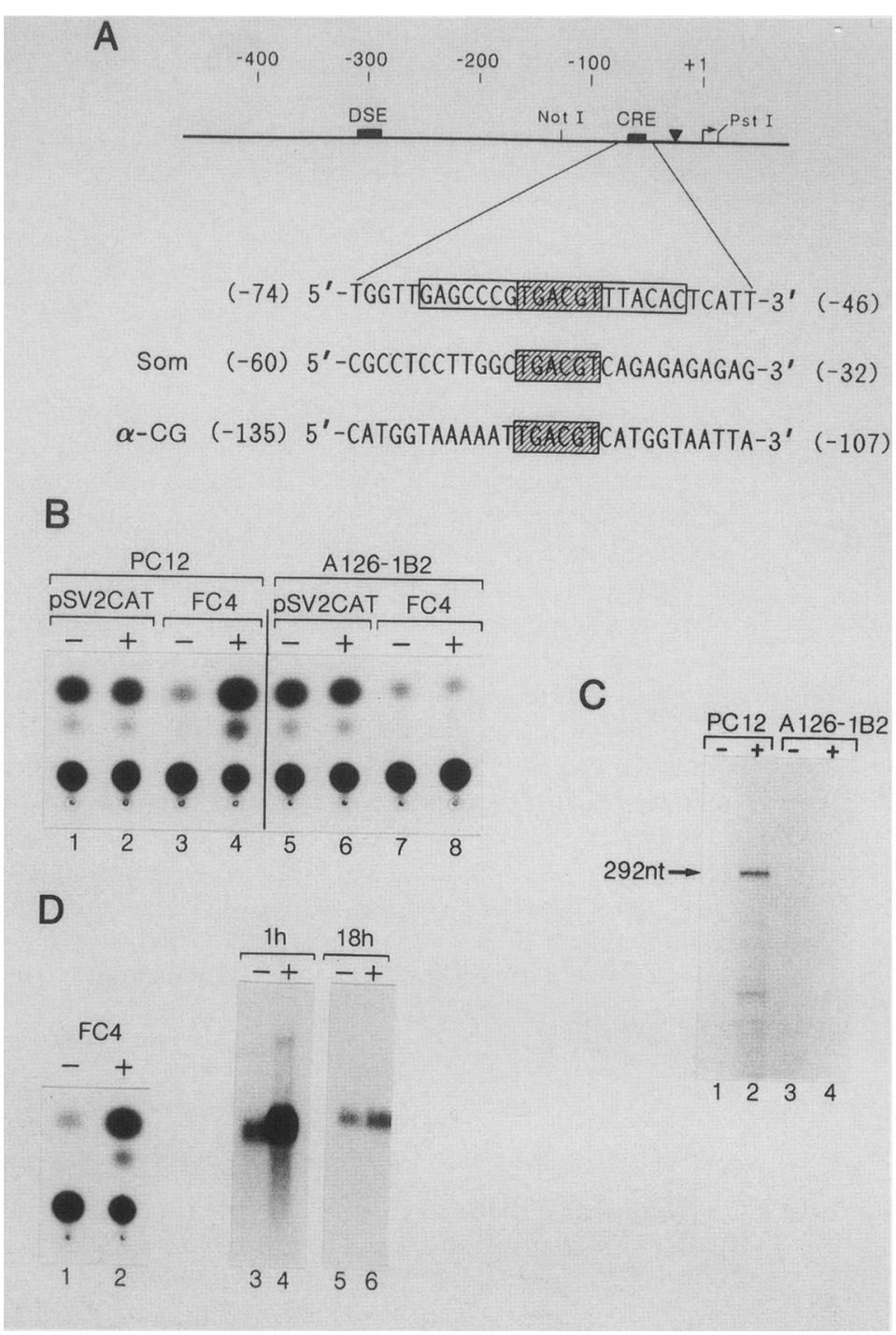

Figure 1. CRE in the human c-fos gene. (A) Structure of the human c-fos promoter (Van Straaten et al. 1983). The positions of the DSE, CRE, TATA-box $(\nabla)$, and the transcription start site are indicated. The NotI and PstI restriction sites were used to prepare a $5^{\prime}$-end-labeled fragment as probe in the DNA footprinting experiments (see Fig. 4). The sequence flanking the c-fos CRE is indicated. The shadowed sequence $5^{\prime}$-TGACGT-3' is the consensus sequence common to cAMP-responsive genes (Montminy et al. 1986; Sassone-Corsi 1988) such as the rat somatostatin (Som) and the human glycoprotein hormone $\alpha$-subunit $(\alpha$-CG). In the case of the $\alpha$-CG gene, the conserved sequence is repeated in tandem (Delegeane et al. 1987); here, only the most downstream repeat is shown. The sequence of the c-fos promoter protected in the DNase I footprinting experiments (see Fig. 4) is boxed (positions -51 to -69 ). $(B)$ Induction of $\mathrm{c}$-fos-CAT fusion gene by forskolin in PC12 cells. PSV2CAT contains the entire SV40 promoter linked to the CAT bacterial gene (Gorman et al. 1982). FC4 is a deletion mutant of the c-fos promoter, where $404 \mathrm{bp}$ of the upstream region are linked to the CAT gene (Deschamps et al. 1985). Transfection of 10 $\mu \mathrm{g}$ plasmid DNA into PC12, A126-1B2, and JEG-3 cells was performed using the calcium phosphate coprecipitation technique (Sassone-Corsi and Verma 1987). The plasmids were transfected into rat $\mathrm{PC} 12$ pheochromocytoma cells (lanes 1-4) and into PC12 mutant cell line A126-1B2, which is deficient in cAMP-dependent protein kinase II (lanes 5-8). $(+\mid$ Forskolin-treated cells; (-) untreated cells. The forskolin induction of FC4 transcription in PC12 cells is about 15-fold, as measured after densitometric scanning of several autoradiograms. (C) RNase protection of fos-CAT RNA after transfection of FC4 plasmid in both $\mathrm{PC1} 2$ and A126-1B2 cells. Treatments were as described for Fig. IB, where CAT activity was measured. The cRNA probe and the experimental details are described in $\mathrm{Ma}$ terials and methods. $(D)$ Induction of the c-fos-CAT and c-fos gene by forskolin in human choriocarcinoma JEG-3 cells. (Lanes 1 and 2) Induction of the transfected FC4 plasmid. (Lanes 3-6) Northern blot analysis of total RNA from induced cells by forskolin for 1 and $18 \mathrm{hr}$. The Northern blot analysis of RNA from JEG-3 cells was performed as described (Mitchell et al. 1986). The probe used in the hybridization was a full-length human c-fos cDNA clone.

serum, TPA, EGF, FGF, NGF, and insulin, and binds a nuclear factor, termed SRF (Verma and Sassone-Corsi 1987). Thus, the c-fos enhancer, which is located around position -300 , with respect to the c-fos transcriptional start site, appears to mediate the activation that involves the protein kinase $C$ cellular pathway (Gilman 1988). To determine whether the DSE is involved in the cAMP response of the c-fos promoter, we carried out transient transfection assays using several c-fos promoter deletions. Mutants that delete the DSE are as cAMP inducible as the complete c-fos promoter, indicating that the sequence required for CAMP induction is located farther downstream of the DSE (in Fig. 2A, the result relative to FC8 is shown). Consequently, the DSE is not responsible for the cAMP inducibility of the c-fos promoter. Other results indicate that a c-fos promoter deletion to position -64 is still cAMP responsive (Verma et al. 1988; P. Sassone-Corsi et al., unpubl.). Furthermore, as already pointed out (Montminy et al. 1986; Sassone-Corsi 1988), a TGACGT sequence found at position -60 is identical to CRE sequence present in cAMP-responsive gene promoters (see also Fig. 1A), such as the rat somatostatin (Montminy et al. 1986), the $\alpha$ chorionic gonadotropin (Delegeane et al. 1987; Silver et al. 1987), and others. The CRE consensus sequence is present only once in the fos promoter, downstream from position -220 . This sequence has been shown to bind a nuclear factor that appears to promote the general expression of this gene (Fisch et al. 1987). When this element was deleted in fos-CAT fusion genes that still re- 


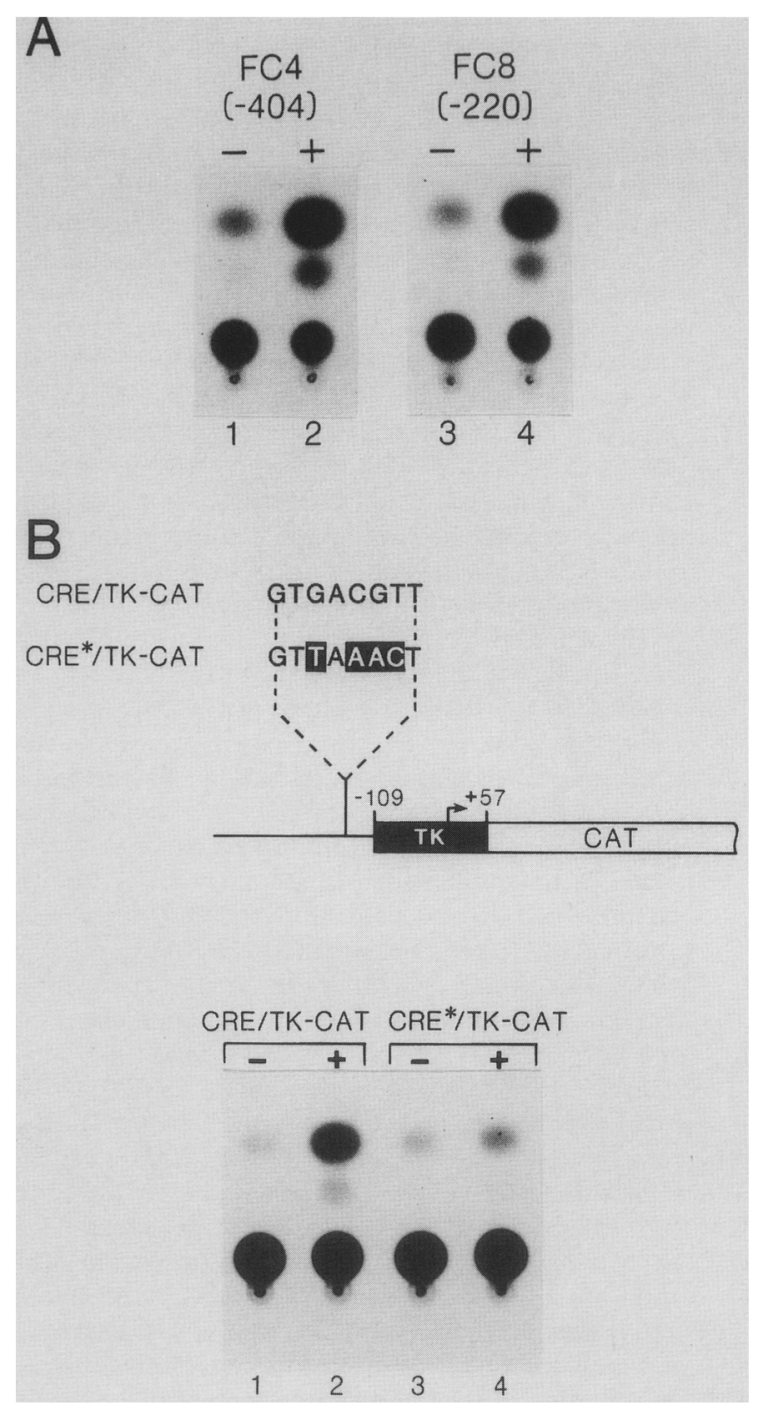

Figure 2. Sequence characterization of the c-fos CRE. $|A|$ Analysis of forskolin induction on the deletion mutants of the c-fos promoter. Several deletions were linked to the CAT gene, and the plasmid DNAs were transfected in PC12 cells as described in Fig. 1. Only the results obtained with FC4 $(-404)$ and FC8 $(-220)$ are shown and are representative of a series of experiments. Quantification of CAT activity was performed by densitometric scanning of several autoradiograms. Induction of c-fos transcription by forskolin for FC4 is about 15 -fold; induction of FC8 is about 10-fold. |+ | Forskolin-treated cells; $|-|$ untreated cells. $(B)$ The $-60 \mathrm{CRE}$-like sequence confers cAMP inducibility to heterologous promoter. TK-CAT (Delegeane et al. $1987)$ is a reporter plasmid containing the herpes simplex virusTK gene promoter (positions -109 to +57 ) linked to the CAT gene. A 30-bp oligodeoxynucleotide bearing the human c-fos -60 region (positions -75 to -46 ; the complete sequence is indicated at the bottom of Fig. 3B/ was inserted upstream of the TK promoter, producing CRE/TK-CAT. CRE*/TK-CAT is equivalent to CRE/TK-CAT, but the CRE contains four point mutations that abolish the consensus sequence (see Fig. $3 \mathrm{~B}$ ). The two plasmids were transfected in $\mathrm{PC} 12$ cells, and cAMP responsiveness was analyzed. (Lane 1-2) CRE/TK-CAT is inducible by forskolin treatment; (lanes 3-4) mutations in the CRE impair cAMP responsiveness. (+ | Forskolin-treated cells; $(-)$ untreated cells. tained the DSE, basal expression in transfection assays was reduced by 10 - to 15 -fold. Also, induction by growth factors and TPA of a c-fos promoter where the -60 element was deleted showed drastic reduction, indicating an additional regulatory role of this element (Fisch et al. 1987).

\section{The -60 region contains a CRE}

To determine whether the TGACGT sequence present between positions -63 and -57 in the c-fos promoter has the properties of a CRE, we synthesized oligodeoxynucleotides that correspond to the c-fos CRE-like sequence. As shown in Figure 2B, two 30-bp oligodeoxynucleotides containing c-fos CREs were cloned upstream of a herpes thymidine kinase (TK) promoter/CAT fusion gene. One synthetic CRE corresponds to the wild-type sequence (referred to as plasmid CRE/TKCAT); the other has the consensus CRE mutated to TTAAAC (CRE*/TK-CAT). The two plasmids were tested for CAMP responsiveness in PC12 cells. As shown in Figure 2B, the wild-type c-fos CRE confers cAMP inducibility on the heterologous herpes TK promoter /cf. lanes 1 and 2), whereas the mutated CRE shows no detectable transcriptional stimulation (cf. lanes 3 and 4). These results indicate that the c-fos -60 promoter element is a functional CRE.

\section{In vivo requirement for a trans-acting factor}

To demonstrate that the CRE in the proximal upstream region of the c-fos promoter is responsible for cAMP induction by interaction with a nuclear trans-acting factors, we performed in vivo competition experiments (Scholer and Gruss 1984) in which increasing amounts of plasmid DNAs containing heterologous CREs from the somatostatin and $\alpha$-CG genes were cotransfected with a fixed amount of a c-fos-CAT gene. For this study we used FC8, a c-fos-CAT recombinant in which only $220 \mathrm{bp}$ of the $\mathrm{c}$-fos promoter are linked to the CAT gene. This fusion gene is still efficiently induced by cAMP, as shown by the deletion analysis (Fig. 2A; see also Fig. 3A, cf. lanes 1 and 6 for PC12 cells and lanes 7 and 10 for JEG-3 cells). Increasing amounts of the $\alpha$-CG and somatostatin CRE-containing plasmids drastically reduced the cAMP induction of the c-fos promoter in PC12 cells (Fig. 3A, lanes 2 and 3, 4 and 5) and JEG-3 cells (lanes 8 and 9; data with the $\alpha$-CG competitor are not shown). Experiments in which the non-cAMP-responsive pSV2CAT plasmid was cotransfected with the heterologous competitors showed no decrease in SV40 promoter activity (data not shown). These results indicate that a trans-acting factor is required for the cAMP response of the c-fos promoter in both PC12 and JEG-3 cells. Furthermore, this factor is probably common to other CREs, as cAMP induction of the c-fos gene can be drastically reduced using heterologous competitors. 


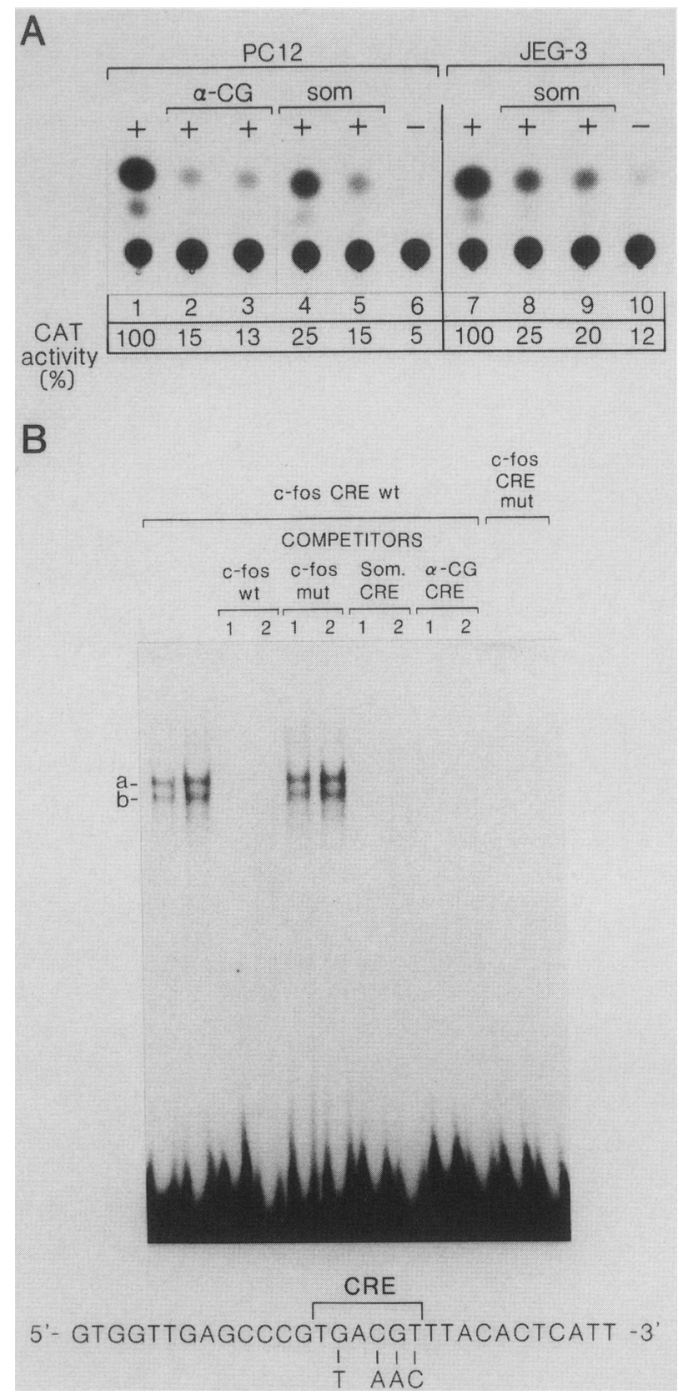

Figure 3. A trans-acting factor is involved in cAMP responsiveness of the c-fos promoter. $(A)$ Competition experiments in PC12 and JEG-3 cells. (Lane 1) CAT activity after transfection of $4 \mu \mathrm{g}$ of FC8 DNA in forskolinstimulated PC12 cells. Increasing amounts of $\alpha$-CG competitor $(15$ and 25 $\mu \mathrm{g}$; lanes 2 and 3 , respectively) decreased the CAT activity of the cotransfected FC8. Increasing amounts of somatostatin competitor $(15$ and $25 \mu \mathrm{g}$; lanes 4 and 5, respectively) show the same effect. (Lane 6) The basal level for the FC8 construct. Similar results were obtained in JEG-3 cells with 15 and $25 \mu \mathrm{g}$ of the somatostatin competitor (cf. lane 7 with lanes 8 and 9). Analogous results were obtained with the $\alpha$-CG competitor (not shown). (Lane 10) The basal level for FC8 in JEG-3 cells. CAT activity was quantified by densitometic scanning of autoradiograms from several experiments. The relative ratio of the observed activity of the various samples to the maximal activity recorded (lanes 1 and 7 ) is expressed as a percentage. The $\alpha$-CG competitor contains two copies of the CRE, which are present in the promoter of the gene (positions -152 to -100 ) cloned into the GEM-4 plasmid. The somatostatin competitor contains the CRE sequence (positions -32 to -61 ) cloned into the GEM-4 plasmid. DNA transfections, forskolin treatments, and CAT assays were performed as described in the legend to Fig. $1 .(+)$ Forskolin-treated cells; $(-)$ untreated cells. The total amount of DNA in each transfection was the same, being adjusted to $30 \mu \mathrm{g}$ with GEM-4 DNA when necessary. $(B)$ In vitro binding studies to the $c$-fos CRE. The same oligodeoxynucleotides that were inserted upsteam of the TK/CAT fusion gene (see Fig. 2B) were end labeled and used in a gel-shift analysis with nuclear extracts from PC12 cells. The wild-type CRE oligodeoxynucleotide (see sequence at the bottom) binds two nucleoprotein complexes ( $a$ and $b$ ), which presumably represent monomer and dimer forms of the same nuclear factor (Yamamoto et al. 1988). The first and last two lanes indicate experiments in which 1 and $2 \mu \mathrm{l}$ of PC12 nuclear extract was used, whereas $2 \mu \mathrm{l}$ of extract was used in all the other lanes. Excess of the cold wild-type c-fos CRE competes the binding efficiently, and well as an excess of heterologous CRE sequences (Som) somatostatin; $(\alpha-\mathrm{CG}) \alpha$ chorionic gonadotropin. The mutated c-fos CRE (see sequence at the bottom) does not bind any nucleoprotein complex and fails to compete with binding on the wild-type CRE sequence. (Lanes 1 and 2) Excesses of 10- and 20-fold of the unlabeled competitor oligodeoxynucleotide. Details are given in Materials and methods.

Specific factors in nuclear extracts bind to the c-fos $C R E$ Gel mobility shift assays with end-labeled oligodeoxynucleotide probes containing the -63 to -57 region of the $\mathrm{c}$-fos promoter showed specific binding of a protein in PC12 nuclear extracts. Binding reactions with the wild-type CRE results in the formation of two high-molecular-weight complexes (Fig. 3B, bands a and b). As already established for the somatostatin CRE (Yamamoto et al. 1988), which is homologous to the c-fos CRE (see Fig. 1Al, the two bands are very likely to represent binding of the same nuclear factor as monomer (lower complex, b) and dimer (higher complex, a). This has been postulated due to perfect symmetry of the CRE-binding site (Yamamoto et al. 1988). That the c-fos CRE binds the same nuclear factor as other CREs is demonstrated by binding-competition experiments with other synthetic CREs. As shown in (Figure 3B), an excess of unlabeled c-fos, somatostatin, and $\alpha$-CG CRE abolish binding to the c-fos CRE. In contrast, the mutated c-fos
CRE oligodeoxynucleotide is not an efficient binding site for nuclear factors and, when added in excess to the binding reaction, does not compete the binding observed on the wild-type c-fos CRE sequence. Thus, the same point mutations that impair transcriptional inducibility by cAMP (Fig. 2B) also abolish the binding of a specific nuclear factor to the consensus CRE sequence. An identical binding pattern was observed using extracts from JEG cells and from PC12 cells treated with forskolin (data not shown). Interestingly, A126-1B2 cells also show the same binding profile, using the somatostatin CRE (M. Montminy, pers. comm.), indicating that the nuclear binding factor preexists in the cell before cAMP induction.

To delineate further the CRE factor-binding site, DNase I footprinting assays using nuclear extracts from JEG-3 and PC12 cells were carried out (only the data for JEG-3 cells is shown). Increasing amounts of the extracts were incubated with a $5^{\prime}$-end-labeled c-fos promoter 
fragment [see Fig. 1 ; NotI $(-120)$ to PstI $(+15)]$. Samples were treated with DNase I and the digestion products resolved on denaturing polyacrylamide gels. We observed a single protected region that covered 19 nucleotides, extending from -51 to -69 , relative to the transcription initiation site (Fig. 4A). The CRE sequence 5'TGACGT- ${ }^{\prime}$, implicated in cAMP induction in vivo, is located in the center of the region protected from DNase I digestion. Nuclear extracts prepared from either forskolin-treated or untreated PC12 and JEG-3 cells pro- tected the $-51 /-69$ region, again suggesting that the CRE-binding factor preexists in the cell.

To establish whether the c-fos CRE-binding protein is the same as that interacting with other CREs, we performed competition experiments in conjunction with the DNA-fooprinting assay. Figure 4B shows that an excess of fragment containing either the somatostatin or the $\alpha$-CG CRE will specifically titrate out the c-fos CRE-binding factor (Fig. 4B; lanes 3-6 and 10-13, respectively), whereas a control fragment does not show

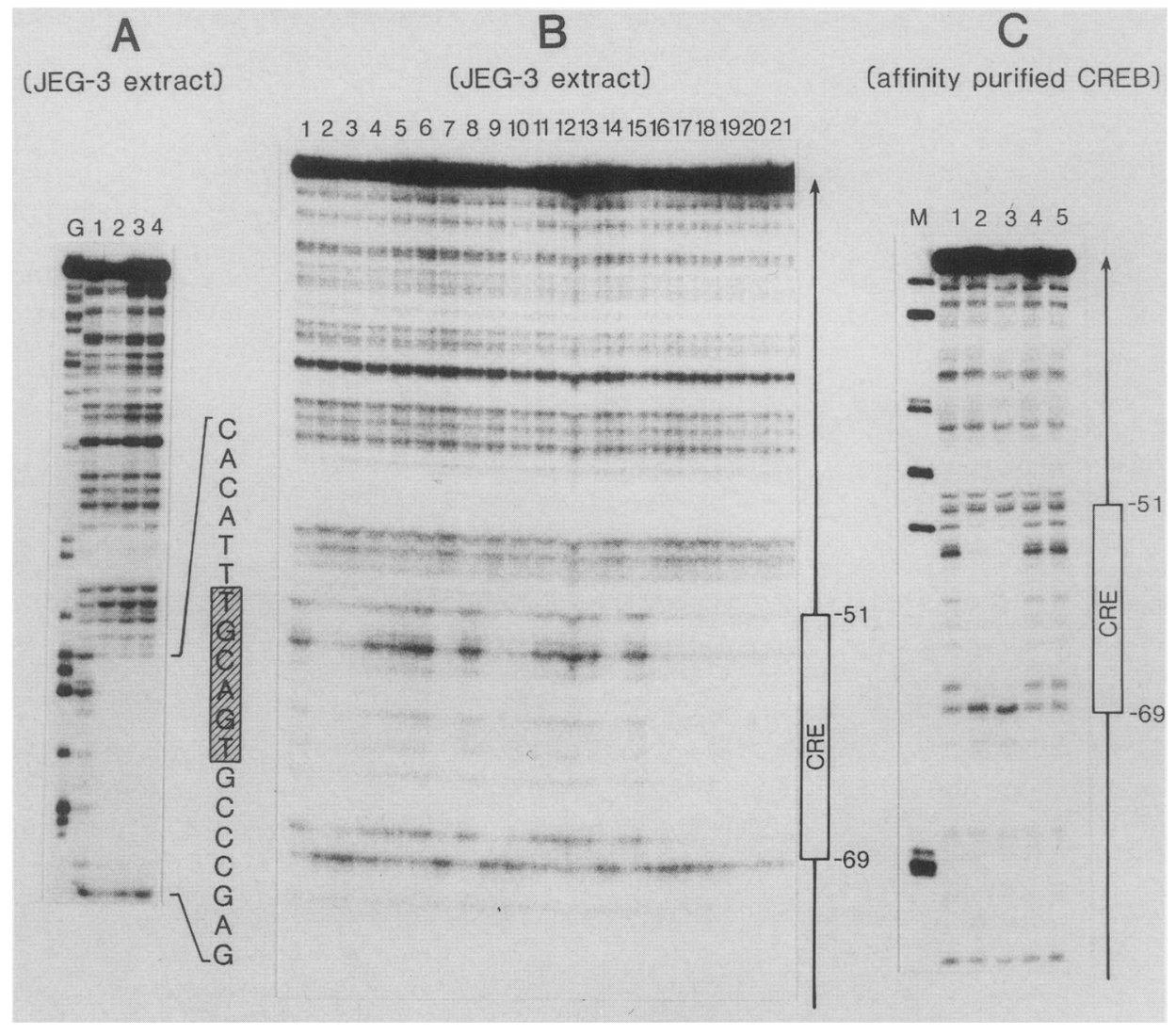

Figure 4. Footprinting of the c-fos CRE by nuclear proteins from JEG-3 and PC12 cells. The DNA fragment of the c-fos promoter used in the footprinting experiments was $5^{\prime}$-end labeled at the NotI site $(-120)$ and extends to the PstI site $(+15)$. Similar results were obtained with different DNA fragments; in particular, the same protected region was observed using a fragment $5^{\prime}$-end labeled on the other strand (not shown). The footprints using nuclear extracts were performed in the presence of $1 \mu \mathrm{g}$ of salmon sperm DNA per binding reaction, as described previously (Delegeane et al. 1987). For the competition experiments, short fragments containing the CREs of either the somatostatin gene $(-61$ to -32$)$ or the $\alpha$-CG gene $(-152$ to -100$)$ were cloned into the polylinker of the GEM-4 plasmid vector. The EcoRI-PvuII fragments were isolated $127 \mathrm{bp}$ for the somatostatin; $133 \mathrm{bp}$ for $\alpha-\mathrm{CG}$; $97 \mathrm{bp}$ for the control fragment containing only GEM-4 sequences) and used in the preincubation reactions. Note that the $\alpha$-CG fragment contains two copies of the CRE (Delegeane et al. 1987). To compete efficiently with the binding activity, we used minimal amounts of the DNA probe $(60 \mathrm{pg})$ and extract $(10 \mu \mathrm{g})$. The footprint reaction using the affinity-purified CREB protein from PC12 cells was performed as described (Montminy and Bilezikjian 1987. (A) Increasing amounts of JEG-3 nuclear extracts (lanes 2-4) show a unique footprint protecting the $-51 /-69$ region from DNase I digestion. (Lane 1) DNase I digestion of the nonprotected DNA fragment. (Lane G) A G sequencing reaction of the 5 '-end-labeled DNA fragment used for the protection experiment. The sequence represents the $-51 /-69$ protected region; the boxed nucleotides are the CRE 'core'. $(B)$ Competition of the c-fos CRE footprint by heterologous CREs (Lanes 1 , 8 , and 15) Control DNase I digests of the probe alone; (lanes 2, 7, 9, 14, 16, and 21) footprint of the $-51 /-69$ region by limiting amounts of nuclear extract from JEG-3 cells; (lanes 3-6) competition by increasing amounts $(6,30,60$, and 300 ng, respectively) of the somatostatin CRE; (lanes 17-20) competition using increasing amounts (as for lanes 3-6) of a control fragment lacking CRE sequences. $(C)$ DNase I footprint of the c-fos CRE by the affinity-purified CREB protein from PC12 cells. (Lane 1) Control DNase I digest of the probe alone; (lanes 2 and 3) footprint on the $-51 /-69$ element by increasing amounts of the CREB protein; (lanes 4 and 5 ) competition for binding when an excess of unlabeled somatostatin (lane 4) and $\alpha$-CG (lane 5) CREs was added to the reaction. 
such competition activity (lanes 17-20). These results are in close agreement with the in vivo competition data (Fig. 3A) and gel mobility shift data (Fig. 3B). Thus, both the binding activity and transcriptional activation are mediated through the same sequence, which is conserved among several cAMP-responsive genes. To determine whether the c-fos CRE-binding factor is actually the same protein that binds to other CREs, we performed DNA footprints using the PC12-derived affinitypurified $43-\mathrm{kD}$ nuclear protein that has been shown to interact specifically with the rat somatostatin CRE (CREB) (Montminy and Bilezikjian 1987). As shown in Figure $4 \mathrm{C}$, the purified $43-\mathrm{kD}$ CREB binds to the c-fos $\mathrm{CRE}$, protecting from DNase I digestion the same $-51 /-69$ regions observed in the footprint experiments performed with nuclear extracts (lanes 2 and 3 ). Furthermore, the binding of the purified protein is also decreased by competitors containing somatostatin and $\alpha$-CG CREs (lanes 4 and 5, respectively).

\section{Discussion}

The physiology of neuroendocrine systems is regulated by complex hormonal actions that stimulate secondmessenger pathways. Two signal transduction mechanisms, the phosphoinositol and cAMP-dependent pathways, acting through specific protein kinases, have been implicated in the generation of second messengers. Several genes are induced by stimulation of adenylate cyclase, presumably via the cAMP-dependent pathway, some of which are activated transcriptionally very rapidly and are known to encode physiologically important neuropeptides and hormones. We have investigated the cAMP induction of the c-fos oncogene, which has been implicated in cell growth, differentiation, and development. Transcription of the fos gene is induced very rapidly by a large variety of mitogenic and differentiationspecific agents. In effect, fos appears to be acting as a sensor that detects incoming signals at the cell membrane and then converts them to long-lasting responses that require gene activity, such as cell division and perhaps even memory formation (Marx 1987). We have shown recently that fos protein has trans-regulatory activity on its own promoter (Sassone-Corsi et al. 1988a) and that it is associated with DNA-binding nuclear factors, such as AP-1 (Rauscher et al. 1988; SassoneCorsi et al. 1988b). These findings open new horizons in the understanding of the kinetics of induction of fos gene expression. In analogy to the repression of seruminduced c-fos transcription where fos is found to be associated with AP-1, we are tempted to speculate the formation of a complex between fos and a CREB-like protein upon cAMP treatment of endocrine-type cells.

We have characterized a sequence of the human c-fos promoter that has the characteristics of a CRE and is located at position -60 with respect to the c-fos transcriptional start site. It has complete identity with CREs from other cAMP-responsive genes (see Fig. 1A; Sassone-Corsi 1988) and confers cAMP inducibility to a heterologous promoter. The fos CRE binds a nuclear factor that has characteristics similar to CREB (Fig. 4) (Montminy and Bilezikjian 1987). Previous results obtained on the somatostatin gene showed that binding of CREB to the CRE occurs as a dimer (Yamamoto et al. 1988). The binding of CREB as a dimer has been demonstrated by UV cross-linking studies and analysis of CRE half-site mutants for their ability to bind purified CREB.

The fact that CREB binds as a dimer is not unexpected due to the perfect symmetry of the CRE site. This is reminiscent of the yeast transcription factor GCN4, which binds as a homodimer to a recognition sequence that has strong homology to the CRE (Hope and Struhl 1987). Using DNA affinity-purified CREB in gel retardation assays with the somatostatin CRE, Yamamoto et al. (1988) observed two complexes that migrated in an analogous fashion to those observed using the c-fos CRE (Fig. 3B). This is particularly interesting because the c-fos CRE does not have two perfect half-sites. Therefore, it is possible that perfect symmetry is not required for dimer formation. Our in vitro competition experiments using unlabeled somatostatin and $\alpha$-CG CREs indicate that the binding to the $\mathrm{c}$-fos CRE is diminished in conditions of both DNA excess (Fig. 3B) and protein excess (Fig. 4). These results, together with the use of somatostatin CRE affinity-purified CREB in a footprinting experiment (Fig. 4C), suggest that the trans-acting factor binding to the c-fos CRE is either CREB or a CREB-like protein. Using in vivo competition experiments, we also demonstrated the requirement of the nuclear factor for transcriptional activation (Fig. 2B). In vitro competition experiments with the same competitor sequences showed a correlation between factor binding and transcriptional activation (Figs. 3B and 4B). These data are corroborated by specific point mutations in the CRE consensus, which eliminate both factor binding (Fig. 3B) and cAMP inducibility in vivo (Fig. $2 \mathrm{~B}$ ). The nuclear factor involved in the cAMP response is present in the cell prior to treatment with agents that stimulate adenylate cyclase, because cell cultures exposed to cycloheximide prior to the addition of forskolin do not show diminished response (Greenberg et al. 1985; Kruijer et al. 1985; Bravo et al. 1987). Furthermore, the presence of CRE-binding activity is detected in untreated cells (Montminy and Bilezikjian 1987; P. Sassone-Corsi et al., unpubl.). The nuclear factor CREB is also abundant in the PC12 mutant cell line A126-1B2 (M. Montminy, pers. comm.), although cAMP responsiveness is diminished drastically in such a cell type, due to the lack of cAMP-dependent protein kinase II (Fig. 1B). These data imply strongly that binding of a CREB-like factor to the CRE is not sufficient for transcriptional activation. CREB additionally requires some type of modification to stimulate transcription which is very likely to be phosphorylation (Yamamoto et al. 1988).

The -60 element has been shown to be involved in the control of the c-fos basal transcription level and regulation of inducibility by calcium (Fisch et al. 1987; Sheng et al. 1988). The data presented here further suggest more than one function for the same regulatory region. Similarly, it has been reported that the CREs 
present in other genes also serve as basal transcription elements (Delegeane et al. 1987; Hurst and Jones 1987; Sassone-Corsi 1988). This implies that they must bind a nuclear factor that is responsible for a basal transcription rate and is likely to be present in the cell at all times. It is possible that the CREB-like factor could function as a basal transcription factor when not modified by phosphorylation. The -60 region is not the only cAMP-inducible element in the c-fos gene. Preliminary results indicate another CRE-like sequence at position -340 , previously identified as the v-sis-condition-medium inducible region (Hayes et al. 1987). There is likely to be yet another cAMP-responsive region downstream of the -60 element (P. Sassone-Corsi, unpubl.).

We identified a CRE sequence in the c-fos promoter that is involved in the transcriptional induction by agonists by cAMP. Previously, the DSE at position -300 has been shown to be required for induction of the c-fos gene via the protein kinase $\mathrm{C}$ pathway. Thus, the regulation of proto-oncogene fos relies on two major pathways of signal transduction and is mediated through two separated promoter elements.

\section{Materials and methods}

\section{Plasmids}

Human c-fos promoter/CAT fusions FC4 and FC8 have been described previously (Deschamps et al. 1985; Sassone-Corsi and Verma 1987). Recombinants CRE/TK-CAT and CRE*/TK-CAT contain 30-bp oligodeoxynucleotides with the wild-type c-fos -60 region (GTGACGTT, CRE) and the mutated version (GTTAAACT, CRE*), respectively (see Fig. $2 \mathrm{~B}$ ). Competitor plasmids som and $\alpha$-CG (see Fig. 3A) contain the somatostatin (positions -32 to -61 ) and the $\alpha$-chorionic gonadotropin (positions -152 to -100 ) CRE sequences, respectively, inserted in the polylinker of the GEM-4 vector. Note that the $\alpha$-CG competitor contains two CRE sequences that are present in the promoter of the gene (Delegeane et al. 1987).

\section{Tissue culture and DNA-mediated transfection}

PC12 pheochromocytoma cells (Greene and Teschler 1982) were grown in Dulbecco's modified Eagle's medium (DMEM), supplemented with $10 \%$ fetal bovine serum and $5 \%$ horse serum. The PC12 mutant cell line A126-1B2 (Van Buskirk et al. 1985) was grown in the same conditions. Human choriocarcinoma JEG-3 cells (Delegeane et al. 1987) were grown in DMEM supplemented with $10 \%$ fetal bovine serum. Cells at $70 \%$ confluence were transfected by the calcium phosphate coprecipitation technique and exposed to the precipitate for $12 \mathrm{hr}$. After washing with PBS, fresh medium containing forskolin was added for 4-8 hr, when required, at a final concentration of $20 \mu \mathrm{M}$. When $<20-30 \mu \mathrm{g}$ of specific DNA was used per $10-\mathrm{cm}$ culture dish, pUC19 plasmid DNA was added to give $20-30 \mu \mathrm{g}$ of total DNA. After DNA transfection, the cells were harvested and CAT assays were performed as described (Gorman et al. 1982).

\section{Isolation and analysis of RNA}

Total cytoplasmic RNA was isolated and RNase protection mapping performed as described (Sassone-Corsi and Verma 1987). Briefly, $30 \mu \mathrm{g}$ of RNA was hybridized with ${ }^{32}$ P-labeled
SP6 cRNA for $16 \mathrm{hr}$ at $45^{\circ} \mathrm{C}$ in $80 \%$ formamide, $40 \mathrm{~mm}$ PIPES (pH 6.4), $400 \mathrm{mM} \mathrm{NaCl}$, and $1 \mathrm{mM}$ EDTA. Following hybridization, samples were treated with a mixture of RNase A 140 $\mu \mathrm{g} / \mathrm{ml})$ and RNase $\mathrm{Tl}(700 \mathrm{U} / \mathrm{ml})$ at $32^{\circ} \mathrm{C}$ for $60 \mathrm{~min}$. The samples were incubated further for $15 \mathrm{~min}$ at $37^{\circ} \mathrm{C}$ after addition of $1 \%$ SDS and $50 \mu \mathrm{g}$ of proteinase $\mathrm{K}$, extracted with phenol/chloroform, ethanol-precipitated, and loaded onto an $8 \%$ sequencing gel. The cRNA fos-CAT probe is 392 nucleotides long, from the EcoRI site in the CAT gene $(+250)$ to the BssHII site in the c-fos promoter $(-100)$. The expected size of the protected fragment is 292 nucleotides, as $42 \mathrm{bp}$ of the c-fos promoter are present in the FC4 fusion construct. Northern analysis of the JEG-3 cells RNA was performed as described (Mitchell et al. 1986).

\section{Nuclear extracts and gel retardation assay}

Nuclear extracts from HeLa cells were prepared essentially as described (Dignam et al. 1983). Final protein concentrations were typically $1-2 \mathrm{mg} / \mathrm{ml}$. DNA-protein binding was conducted in $20-\mu l$ volumes. Nuclear extract $(1-3 \mu l)$ was incubated with $1 \mu \mathrm{g}$ of poly(dI : dC) (Boehringer-Mannheim) in TM buffer (Lee et al. 1987; Sassone-Corsi et al. 1988b) for $20 \mathrm{~min}$ at room temperature. A synthetic 30 -bp oligodeoxynucleotide containing the human c-fos CRE was end-labeled with $\left[\gamma^{-32} \mathrm{P}\right] \mathrm{ATP}$, using T4 polynucleotide kinase. Approximately 0.1 ng of ${ }^{32} \mathrm{P}$-labeled DNA $<10,000 \mathrm{cpm} /$ was added to the preincubated nuclear extract or protein fractions. Unlabeled competitor DNA was added to the binding reaction $2 \mathrm{~min}$ before the labeled oligomer. DNA-protein complexes were resolved on a $4 \%$ polyacrylamide gel (38:2 acrylamide to bis-acrylamide) in $0.25 \times$ TBE $[1 \times$ TBE is $50 \mathrm{~mm}$ Tris-borate $(\mathrm{pH} 8.3)$ and $1 \mathrm{mM}$ EDTA]. The gels were dried and autoradiographed with intensifying screens at $-70^{\circ} \mathrm{C}$.

\section{Footprinting assay}

The DNA fragment of the c-fos promoter used in the footprinting experiments was 5 -end labeled at the NotI site $(-120)$ and extended to the PstI site $(+15)$. Similar results were obtained with different DNA fragments, including a fragment 5 ' end labeled on the other strand (not shown). The footprints using nuclear extracts were performed in the presence of $1 \mu \mathrm{g}$ of salmon sperm DNA per binding reaction, as described previously (Delegeane et al. 1987). For the competition experiments, short fragments containing the CREs of either the somatostatin gene $(-61$ to -32$)$ or the $\alpha$-CG gene $(-152$ to -100 ) were cloned into the polylinker of the GEM-4 plasmid vector. The EcoRI-PvuII fragments were isolated (a 127-bp somatostatin fragment; a 133-bp $\alpha$-CG fragment; a 97-bp control fragment containing only GEM-4 sequences) and used in the preincubation reactions. Note that the $\alpha$-CG fragment contains two copies of the CRE (Delegeane et al. 1987). To compete with the binding activity efficiently, we used minimal amounts of the DNA probe $(60 \mathrm{pg})$ and extract $(10 \mu \mathrm{g})$. The footprint reactions using the affinity-purified CREB protein from PC12 cells were performed as described (Montminy and Bilezikjian 1987).

\section{Acknowledgments}

We are particularly grateful to Dr. Marc Montminy for the generous gift of the affinity-purified CREB protein from $\mathrm{PCl} 2$ cells. We thank Dr. J. Wagner for the A126-1B2 cell line and J. Sisson and $M$. Kirven for technical assistance. P. Sassone-Corsi is supported by the American Cancer Society and is on leave from the Laboratoire de Genetique Moleculaire des Eucaryotes, CNRS, 
Strasbourg, France. J.E. Visvader is the recipient of a Jane Coffin Childs Memorial Fund Fellowship. L.B. Ferland is the recipient of a Canadian Medical Research Council postdoctoral fellowship. The work reported here was supported by grants from the National Institutes of Health (to I.M.V. and P.L.M.) and the American Cancer Society, Inc. (I.M.V.).

\section{References}

Angel, P., M. Imagawa, R. Chin, B. Stein, R.J. Imbra, H.J. Rahmsdorf, C. Jonat, P. Herrlich, and M. Karin. 1987. Phorbol ester-inducible genes contain a common cis element recognized by a TPA-modulated trans-acting factor. Cell 49: 729-739.

Bravo, R., N. Manfred, J. Burckhardt, J. Almendral, R. Wallich, and R. Muller. 1987. Involvement of common and cell typespecific pathways in c-fos gene control: Stable induction by cAMP in macrophages. Cell 48: 251-260.

Cochran, B.H., A.C. Reffel, and C.D. Stiles. 1983. Molecular cloning of gene sequences regulated by platelet-derived growth factor. Cell 33: 939-947.

Curran, T. and J.T. Morgan. 1985. Superinduction of the c-fos by nerve growth factor in the presence of peripherally active benzodiazapines. Science 229: 1265-1268.

Delegeane, A.M., L.H. Ferland, and P.L. Mellon. 1987. Tissue specific enhancer of the human glycoprotein hormone $\alpha$ subunit gene: Dependence upon cyclic AMP inducible elements. Mol. Cell. Biol. 7: 3994-4002.

Deschamps, J., F. Meijlink, and I.M. Verma. 1985. Identification of a transcriptional enhancer element upstream from the proto-oncogene fos. Science 230: 1174-1177.

Dignam, J.D., R.M. Lebowitz, and R.G. Roeder. 1983. Accurate transcription initiation by RNA polymerase II in a soluble extract from isolated mammalian nuclei. Nucleic Acids Res. 11: $1475-1489$.

Fisch, T.M., R. Prywes, and R.G. Roeder. 1987. c-fos sequences necessary for basal expression and induction by epidermal growth factor, 12-0-tetradecanoyl phorbol-13-acetate, and the calcium ionophore. Mol. Cell. Biol. 7: 3490-3502.

Gilman, M.Z. 1988. The c-fos senum response element responds to protein kinase C-dependent and -independent signals but not to cyclic AMP. Genes Dev. 2: 394-402.

Gilman, M.Z., R.N. Wilson, and R.A. Weinberg. 1986. Multiple protein-binding sites in the $5^{\prime}$-flanking region regulate c-fos expression. Mol. Cell. Biol. 6: 4305-4316.

Gorman, C.M., L.F. Moffat, and B.H. Howard. 1982. Recombinant genomes which express chloramphenicol acetyltransferase in mammalian cells. Mol. Cell. Biol. 2: 1044-1051.

Greenberg, M.E. and E.B. Ziff. 1984. Stimulation of 3T3 cells induces transcription of the c-fos proto-oncogene. Nature 311: 433-438.

Greenberg, M.E., L.A. Greene, and E.B. Ziff. 1985. Nerve growth factor and epidermal growth factor induce rapid transient changes in proto-oncogene transcription in $\mathrm{PCl} 2$ cells. J. Biol. Chem. 260: 14101-14110.

Greenberg, M.E., Z. Siegfried, and E.B. Ziff. 1987. Mutation of the $c$-fos gene dyad symmetry element inhibits serum inducibility of transcription in vivo and the nuclear regulatory factor binding in vitro. Mol. Cell. Biol. 7: 1217-1225.

Greene, L.A. and A.S. Teschler. 1982. PC12 pheochromocytoma cultures in neurobiological research. Adv. Cell. Neurobiol. 3: 373-414.

Hayes, T.E., A.M. Kitchen, and B.H. Cochran. 1987. Inducible binding of a factor to the c-fos regulatory region. Proc. Natl. Acad. Sci. 84: 1272-1276.
Hope, I.A. and K. Struhl. 1987. GCN4, a eukaryotic transcriptional activator protein, binds as a dimer to target DNA. $E M B O$ J. 6: 2781-2784.

Hurst, H.C. and N.C. Jones. 1987. Identification of factors that interact with the E1A-inducible adenovirus E3 promoter. Genes Dev. 1: 1132-1146.

Kruijer, W., D. Schubert, and I.M. Verma. 1985. Induction of the proto-oncogene fos by nerve growth factor. Proc. Natl. Acad. Sci. 82: 7330-7334.

Kruijer, W., J.A. Cooper, T. Hunter, and I.M. Verma. 1984. Platelet-derived growth factor induces rapid but transient expression of the c-fos gene and protein. Nature 312: 711716.

Lee, W., P. Mitchell, and R. Tjian. 1987. Purified transcription factor AP-1 interacts with TPA-inducible enhancer elements. Cell 49: 741-752.

Lin, Y.-S. and M.R. Green. 1988. Interaction of a common cellular transcription factor, ATF, with regulatory elements of both E1A and cyclic AMP inducible promoters. Proc. Natl. Acad. Sci. 85: 3396-3400.

Marx, J.L. 1987. The fos gene as 'Master Switch'. Science 237: 854-856.

Mitchell, R.L., C. Henning-Chubb, E. Huberman, and I.M. Verma. 1986. c-fos expression is neither sufficient nor obligatory for differentiation of monomyelocytes to macrophages. Cell 45: 497-504.

Montminy, M.R. and L. Bilezikiian. 1987. Binding of a nuclear protein to the cyclic-AMP response element of the somatostatin gene. Nature 328: 175-178.

Montminy, M.R., K.A. Sevarino, J.A. Wagner, G. Maudel, and R.H. Goodman. 1986. Identification of a cyclic-AMP-responsive element within the rat somatostatin gene. Proc. Natl. Acad. Sci. 83: 6682-6686.

Morgan, J.I., D.R. Cohen, J.L. Hempstead, and T. Curran. 1987. Mapping patterns of c-fos expression in the central nervous system after seizure. Science 237: 192-197.

Muller, R. 1986. Cellular and viral fos genes: Structure, regulation of expression and biological properties of their encoded products. Biochim. Biophys. Acta 823: 207-225.

Prywes, R. and G. Roeder. 1986. Inducible binding of a factor of the c-fos enhancer. Cell 47: 777-784.

Rauscher, F.J. III, D.R. Cohen, T. Curran, T.J. Bos, P. Vogt, D. Bohmann, R. Tjian, and R. Franza, Jr. 1988. fos-associated protein p39 is the product of the jun proto-oncogene. Science 240: 1010-1015.

Sassone-Corsi, P. 1988. Cyclic-AMP induction of early adenovirus promoters involves sequences required for ElA transactivation. Proc. Natl. Acad. Sci. 85: 7192-7196.

Sassone-Corsi, P. and E. Borrelli. 1987. Promoter trans-activation of c-fos and c-myc, but not c-Ha-ras, by products of adenovinus early region 1A. Proc. Natl. Acad. Sci. 84: 64306433.

Sassone-Corsi, P. and I.M. Verma. 1987. Modulation of c-fos gene transcription by negative and positive cellular factors. Nature 326: 507-510.

Sassone-Corsi, P., J.C. Sisson, and I.M. Verma. 1988a. Transcriptional autoregulation of the proto-oncogene fos. Nature 334: 314-319.

Sassone-Corsi, P., W.W. Lamph, M. Kamps, and I.M. Verma 1988 b. fos-associated cellular p39 is related to nuclear transcription factor AP-1. Cell 54: 553-560.

Scholer, H.R. and P. Gruss. 1984. Specific interactions between enhancer-containing molecules and cellular components. Cell 36: 403-411.

Sen, R. and D. Baltimore. 1986. Inducibility of $\kappa$ immunoglobulin enhancer-binding protein NF- $\mathrm{BB}$ by a posttranslational 
mechanism. Cell 47: 921-928.

Sheng, M., S.T. Dougan, G. McFadden, and M.E. Greenberg. 1988. Calcium and growth factor pathways of c-fos transcriptional activation require distinct upstream regulatory sequences. Mol. Cell. Biol. 8: 2787-2796.

Silver, B.J., J.A. Bokar, J.B. Virgin, E.A. Vallen, A. Milsted, and J.H. Milson. 1987. Cyclic AMP regulation of the human glycoprotein hormone $\alpha$-subunit gene is mediated by an 18-pair element. Proc. Natl. Acad. Sci. 84: 2198-2202.

Sorger, P.K., M.J. Lewis, and H.R.B. Pelham. 1987. Heat shock factor is regulated differently in yeast and HeLa cells. $\mathrm{Na}$ ture 329: 81-84.

Terao, M., Y. Watanabe, M. Mishina, and S. Numa. 1983. Sequence requirement for transcription in vivo of the human preproenkephalin A gene. EMBO I. 2: 2223-2228.

Treisman, R. 1985. Transient accumulation of c-fos RNA following serum stimulation requires a conserved $5^{\prime}$ element and c-fos 3' sequences. Cell 42: 889-902.

. 1986. Identification of a protein-binding site that mediates transcriptional response of the c-fos gene to serum factors. Cell 46: 567-574.

Van Buskirk, R., T. Corcoran, and J.A. Wagner. 1985. Clonal variants of $\mathrm{PCl} 2$ pheochromocytoma cells with defects in cAMP-dependent protein kinases induce ornithine decarboxylase in response to nerve growth factor but not to adenosine agonists. Mol. Cell. Biol. 5: 1984-1992.

Van Straaten, F., R. Muller, T. Curran, C. Van Beveren, and I.M. Verma. 1983. Nucleotide sequence of a human c-onc gene: Deduced amino acid sequence of human c-fos protein. Proc. Natl. Acad. Sci. 80: 3183-3187.

Verma, I.M. 1986. Proto-oncogene fos: A multifaceted gene. Trends Genet. 2: 93-96.

Verma, I.M. and P. Sassone-Corsi. 1987. Proto-oncogene fos: Complex but versatile regulation. Cell 51: 513-514.

Verma, I.M., J. Visvader, W.W. Lamph, P. DeTogni, J. Barber, and P. Sassone-Corsi. 1988. Regulation of fos gene: A paradigm for nuclear oncogenes. In UCLA Symposium, 'Growth factors and their receptors: Genetic control and rational application' (in press).

Visvader, I., P. Sassone-Corsi, and I.M. Verma. 1988. Two adjacent promoter elements mediate nerve growth factor activation of the $\mathrm{c}$-fos promoter and bind distinct nuclear complexes. Proc. Natl. Acad. Sci. (in press).

Yamamoto, K.K., G.A. Gonzalez, W.H. Biggs III, and M.R. Montminy. 1988. Phosphorylation-induced binding and transcriptional efficacy of nuclear factor CREB. Nature 334: 494-498. 


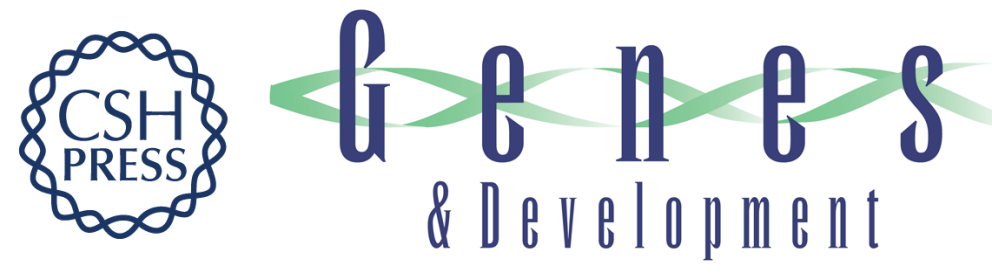

\section{Induction of proto-oncogene fos transcription through the adenylate cyclase pathway: characterization of a cAMP-responsive element.}

P Sassone-Corsi, J Visvader, L Ferland, et al.

Genes Dev. 1988, 2:

Access the most recent version at doi:10.1101/gad.2.12a.1529

References This article cites 48 articles, 23 of which can be accessed free at:

http://genesdev.cshlp.org/content/2/12a/1529.full.html\#ref-list-1

License

Email Alerting

Service

Receive free email alerts when new articles cite this article - sign up in the box at the top right corner of the article or click here.

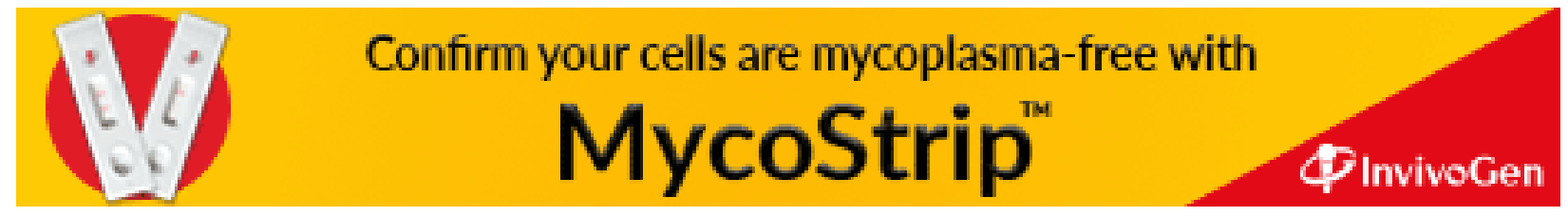

